\title{
OPapel da Comunicação no Controle do Câncer em Tempos de Fake News: Uso Técnico e Ético das Novas Tecnologias na Transmissão de Informações ao Público sobre a Doença
}

https://doi.org/10.32635/2176-9745.RBC.2021v67n2.1881

\author{
The Role of Communication in Cancer Control in Times of Fake News: Technical and Ethical Use of New Technologies in \\ Disclosing Information to the Public about the Disease \\ El Papel de la Comunicación en el Control del Cáncer en Tiempos de Fake News: Uso Técnico y Ético de las Nuevas Tecnologías \\ en la Transmisión de Información al Público sobre la Enfermedad
}

Nemézio Amaral Filho'

\section{INTRODUÇÃO}

No momento em que este ensaio é produzido, as novas tecnologias de informação parecem dar razão àqueles que criticavam a ideia - presente ao menos desde o século XIX de que seu desenvolvimento e popularizaçáo aproximariam os diferentes ${ }^{1}$, ao mesmo tempo em que póem em xeque aqueles que acentuaram com muita ênfase os benefícios de descobertas comunicacionais como a Internet ${ }^{2}$, que permitiram a "libertação da palavra" das pessoas que não tinham suas tribunas midiáticas, proporcionando, assim, a assunção da "consciência coletiva", esta que levaria a inteligência social a um nível mais alto.

$\mathrm{O}$ ambiente profundamente polarizado em quase todo o Ocidente democrático atual mostra que algo não funcionou exatamente como os "integrados" (defensores de primeira hora das novas tecnologias) haviam sugerido.

De maneira mais ou menos apressada e com muita simpatia de empresários do setor, decretou-se a desnecessidade do profissional de Comunicação Social, notadamente aquele que deveria trabalhar com informação mais objetiva (objetividade entendida aqui enquanto método narrativo, e não "imparcialidade", discussão academicamente superada): o jornalista. Qualquer um passou a poder produzir conteúdo, que quase sempre arbitrariamente é batizado com o nome de "informação" ou "notícia". Entretanto, farto material recentemente investigado, em campos distintos do saber, como o da Sociologia ${ }^{3}$, da Comunicação ${ }^{4}$ e da Matemática ${ }^{5}$, entre outros, mostraram que, mais uma vez, a eterna promessa de superação das barreiras discursivas entre e no interior de comunidades nacionais não se confirmou. Longe disso.

$\mathrm{O}$ crescimento nunca antes visto de possibilidades enunciativas estimulou movimentos políticos que vão dos anos 1990, com Chiapas, no México, à invasão do Capitólio americano, organizada pelas redes sociais e pela dark web - e aqui, por uma questão de circunscrição ao nosso tema, não nos deteremos nas óbvias distinçôes ideológicas entre os dois movimentos. São apenas exemplos pontuais que ilustram a gigantesca dificuldade que é produzir sentido, por meio da comunicação, mas principalmente a de "caráter jornalístico", sobre os temas de maior relevo social. Essa dificuldade também se verifica na defesa da saúde pública. Profundamente inserida nesse embate, a temática do câncer, segunda doença que mais mata no Brasil, é nossa preocupação última no debate aqui proposto. O que nos interessa, portanto, é provocar a discussão de como essa "liberação da palavra"” se inscreve na temática da saúde em geral e na do câncer, em particular em tempos de fake news.

\section{DESENVOLVIMENTO}

\section{SINAIS DE ALERTA E DISPUTAS DISCURSIVAS}

Todas essas transformaçóes tecnológicas comunicacionais afetaram a sociedade brasileira, que já vinha declarando explicitamente, em pesquisas quantitativas, ano após ano, ter dificuldades para distinguir notícias falsas das verdadeiras. Isso logo atingiria a confiabilidade das informaçóes emitidas ao cidadão por órgáos públicos e privados ${ }^{6}$. Os alertas dados não foram suficientemente sistematizados e enfrentados, talvez porque a extensão do dano não pudesse ser prevista no mesmo momento em que as novas tecnologias eram conhecidas pelo público especializado ou não. Ficou claro que, em algum momento, mesmo as informaçóes emanadas por órgãos de saúde de sólida e histórica reputação seriam questionadas, independentemente de fundamentação fática. Era uma questâo de tempo.

${ }^{1}$ Instituto Nacional de Câncer José Alencar Gomes da Silva (INCA). Universidade do Estado do Rio de Janeiro (Uerj). Rio de Janeiro (RJ), Brasil. Orcid iD: https://orcid. org/0000-0002-3902-2800

Endereço para correspondência: Nemézio Amaral Filho. Rua Marquês de Pombal, 125 - 4º andar - Centro. Rio de Janeiro (RJ), Brasil. CEP $20230-240$.

E-mail: nemezio.filho@gmail.com 
Um exemplo discursivamente relevante - discurso aqui entendido em sentido foucaultiano, ou seja, como um fim de poder em si $^{7}$ - é a campanha antivacinal que tem terreno fértil nas redes sociais digitais. A Fundação Oswaldo Cruz, por exemplo, produziu uma análise exploratória em que constatou $13,5 \%$ de engajamento nos links mais compartilhados do Facebook, Twitter, Pinterest e Reddit acerca de fake news sobre vacinas. Por outro lado, a mesma pesquisa mostra que a preocupaçáo com a veracidade gera mais engajamento quando se recorre, para ficarmos apenas em uma ferramenta recente nesses tempos de pós-verdade, às agências de fact checking (checagem de fatos) $^{8}$

Mas só essas açôes espontâneas de busca de informação confiável por parte da própria sociedade claramente não são suficientes. Essa constatação é menos óbvia do que, num primeiro momento, poderia parecer a muitos. $\mathrm{O}$ crescimento dos usos das redes sociais, em especial as redes fechadas de WhatsApp e, mais recentemente, as do Telegram, no caso brasileiro, expôs o país ao que chamamos de analfabetismo funcional digital. Dito de outro modo, trata-se da capacidade de se saber usar as funcionalidades destinadas ao usuário final de uma ferramenta digital on-line, mas não de interagir criticamente com ela, abdicando de grande parte da interpretaçáo político-social sobre a tecnologia.

Essa necessidade de interaçáo crítica vai além de uma relação meramente instrumental. A superação da simples instrumentalidade limitaria a submersão ao fetichismo tecnológico (por exemplo, eu acho que é verdade porque veio de um suporte de mídia que meus iguais manipulam) que provoca danos concretos à saúde pública, consequência indireta do marketing incessante que tece louvores às maravilhas do progresso da "mídia para todos" levado a cabo pelas Big Techs.

Mas é improvável que haja mudança desse quadro no curto prazo. Grosso modo, seria necessário garantia de acesso de crianças das diferentes camadas sociais a escolas que, efetivamente, atuassem com educação digital, proporcionando o desenvolvimento de habilidades técnicas e críticas cada vez mais urgentes ao exercício da cidadania contemporânea, criando, desde cedo, "alfabetização tecnológica" de professores e alunos ${ }^{9}$. Essa educação continuada deveria se estender, pelo menos, até ao ensino médio.

\section{NOVAS HABILIDADES PARA 0 MESMO COMPROMISSO ÉTICO}

Como a educação crítica acerca do digital - que qualificaria o debate público, inclusive quanto à temática da saúde -, mesmo que já estivesse em curso não traria os resultados esperados no curto prazo para mitigar as informaçóes falsas que grassam na Internet, principalmente nas redes sociais, é preciso olhar alternativas mais viáveis neste momento. Por isso, mas não só, o papel do profissional de Comunicação Social, tanto em termos acadêmicos quanto corporativos, ganha relevo. $\mathrm{E}$ aqui assumimos que nos referimos aos profissionais de comunicação dos organismos públicos e privados que tratam da temática da Saúde conscientes do compromisso constitucionalmente esperado de sua atividade com o desenvolvimento social, humanístico e civilizatório. A atividade da Comunicação Social é, sobretudo, um compromisso ético sem o qual o estatuto de verdade (aquela que resiste à contraprova do contraditório) perde sentido com consequências desastrosas para o campo social, como temos verificado no que tange à transmissão de informações científicas.

Um exemplo desse desastre é revelado por Monari e Bertolli Filho ${ }^{10}$, que traçaram um quadro preocupante sobre as notícias falsas detectadas pelo Ministério da Saúde sobre a transmissão de informaçôes de temas diretamente afeitos à pasta. Sobre o câncer, entre as "notícias" detectadas e desmentidas - infelizmente sem a mensuração do impacto da mentira em relação à correção pela ciência -, estão: que há ervas contra o câncer; que determinado hospital encontrou "a cura"; ou que o uso de certo aparelho provoca câncer em alguma parte do corpo etc.

Ainda que muito importantes, nos parece claro que as páginas estáticas nos sites de órgãos públicos de saúde e de iniciativas isoladas no setor privado, que pretendem estimular a busca ativa e embasada da população, não dão conta dos desafios comunicacionais contemporâneos no combate às fake news. Por óbvio, o uso das fake news, tendo as informaçôes de saúde como vítimas, não é uma particularidade brasileira ou encontra na temática do câncer seu alvo exclusivo, como constata-se nas aberraçóes narrativas em torno da doença pelo coronavírus 2019 (do inglês, coronavirus disease 2019 - Covid-19) nos Estados Unidos, com fortes coloraçóes políticas, mostradas, por exemplo, por Chen et $\mathrm{al}^{3}$.

Exatamente por isso, defendemos que o novo embate discursivo pressupóe requalificação de habilidades do profissional de Comunicação Social. Isso demanda o necessário diálogo técnico, mais profundo, com outras áreas do saber, fundamentalmente com aquelas mais afeitas às novas tecnologias comunicacionais. A luta pelas narrativas sobre o câncer vem exigindo pressa na construção desse novo profissional, o que, no caso brasileiro fundamentalmente, não parece encontrar soluçấo apenas no mercado ou nos cursos superiores de Comunicação isoladamente.

Por exemplo, se, de um lado, a pesquisa em câncer começa a descobrir as potencialidades do big data nas investigaçóes populacionais sobre a doença no Brasil ${ }^{11}$, de 
outro, os profissionais de comunicação veem-se às voltas com alteraçóes profundas provocadas pela computarização (não apenas on-line) da produção, circulação, distribuição e consumo de informaçôes, principalmente aquelas afeitas às rotinas jornalísticas (ou da transmissão de informaçôes em formato jornalístico), subitamente tendo que conviver com a linguagem da Inteligência Artificial (IA) ${ }^{12}$. Essa tecnologia, no entanto, só inicia seu uso nos principais veículos de produção de notícias no mundo de forma e intensidade distintas. No Brasil, há, ainda, uma certa incompreensão do real impacto da IA no processo comunicacional como um todo, da gestão ao produtor de conteúdo informativo, como começou a demonstrar Araújo ${ }^{13}$.

\section{UM NOVO COMUNICADOR}

Para que essas ferramentas possam ser utilizadas na comunicação proativa de informaçôes relevantes numa política de controle do câncer, será preciso corrigir enormes lacunas, tanto teóricas quanto práticas, que o desenvolvimento tecnológico abriu no interior no Campo da Comunicação: o que se aprendeu até ontem continua sendo relevante, mas não é mais suficiente para o amanhã.

Cada vez mais vai se exigir que os profissionais de comunicação em geral sejam capazes de questionar os algoritmos que auxiliam, ou substituem completamente a tomada de decisão de muitas categorias profissionais, da Justiça à Saúde ${ }^{13}$. Mais do que apresentar respostas, é preciso estar tecnicamente preparado para elaborar perguntas mais precisas: por que há insistência no uso de algoritmos black box (por meio dos quais a máquina toma decisôes, dá notas, seleciona, mas oculta os critérios de seus modelos de decisão do escrutínio público) nos sistemas de recomendações de informaçôes? Esses algoritmos têm nos levado, como em outros casos, a bolhas de informação sobre o câncer nas redes sociais? Se sim, como isso pode ser evitado no âmbito da comunicaçáo? A habilidade de construção de discursos em linguagem de programação ${ }^{14}$ auxiliaria na contranarrativa às fake news sobre o câncer? Numa atividade de categorizaçáo, um algoritmo pode estigmatizar alguém com câncer no processo de encaminhar ou não uma informação?

O esforço para essas novas habilidades ("novas" como exigências para os profissionais de comunicação) práticas e analíticas já exige o empenho de universidades, órgãos públicos e empresas de mídia tradicional e alternativa que, num primeiro momento, precisarão aproximar programadores, cientistas de dados e estatísticos dos profissionais/estudantes de Comunicação para que essas lacunas sejam supridas, como já se verifica nos Estados Unidos $^{14-17}$.

Esse movimento precisa ser incentivado pelo menos até que o novo comunicador, em meio à crise ética e técnica do campo, esteja pronto enquanto categoria profissional para os diferentes mercados, a exemplo do da Saúde, que necessitam com premência de novas possibilidades de apuração, tradução e exibição de dados, mensuráveis ou não. Como já defendemos em outro lugar ${ }^{18}$, esses profissionais precisarão ainda de uma sólida capacidade de entendimento, de maneira socialmente crítica, do uso das novas tecnologias comunicacionais neste mundo prenhe de dados, o que explica o poderio das Big Techs.

Isso tudo é construído em meio às críticas - tanto as justas quanto as injustas - feitas contra o mercado concentrado da mídia brasileira de um lado, o que, entre outras coisas, facilita o surgimento de teorias conspiratórias contra a saúde; de outro, a relativa incapacidade desse mesmo mercado em atingir segmentos cada vez mais distintos de um tecido social profundamente esgarçado. Como isso não afetaria as informações relativas ao câncer, que ainda têm nesses veículos seus principais parceiros de promoção da saúde?

\section{CONCLUSÃO}

O primeiro passo, acreditamos, é reconhecer as transformações que culminam com o fato de que imprecisóes e mentiras disputam, e muitas vezes vencem, os embates discursivos com a ciência e com a comunicação social responsável, jornalística ou não. $\mathrm{O}$ segundo, é assumir que açôes de desinformação com os mais diferentes interesses se enfrentam com ainda mais ciência e qualificação técnica.

Obviamente, isso não retira a necessidade de se repensar os modelos legais que mexem com interesses há muito estabelecidos. Mas, desde já, temos como certo que um outro profissional de comunicação precisa ser possível.

\section{CONTRIBUIÇÕES}

O autor participou de todas as etapas do manuscrito e aprovou a versão final a ser publicada.

\section{DECLARAÇÃO DE CONFLITO DE INTERESSES}

Nada a declarar.

\section{FONTES DE FINANCIAMENTO}

Não há.

\section{REFERÊNCIAS}

1. Mattelart A. Une éternelle promesse: les paradis de la communication. Le Monde Diplomatique [Internet]. 1995 Nov [cited 2020 Feb 3];Dossier:[about 2 p.]. 
Available from: https://www.monde-diplomatique. fr/1995/11/MATTELART/6768

2. Lemos A, Lévy P. O futuro da Internet: em direção a uma ciberdemocracia planetária. São Paulo: Paulus; 2012.

3. Chen E, Chang H, Rao A, et al. COVID-19 misinformation and the 2020 U.S. presidential election. HKS Misinformation Review. 2021 Mar;1(7). doi: https://doi.org/10.37016/mr-2020-57

4. Da Empoli G. Os engenheiros do caos: como as fake news, as teorias da conspiração e os algoritmos estão sendo utilizados para disseminar ódio, medo e influenciar eleiçôes. São Paulo: Vestígio; 2020.

5. O’Neil C. Algoritmos de destruição em massa: como o big data aumenta a desigualdade e ameaça a democracia. Santo André (SP): Ed. Rua do Sabão; 2020.

6. Amaral Filho N, Murad EG. Esfera pública em crise: o papel da comunicação estratégica e pública em meio à instabilidade institucional brasileira. In: $40^{\circ}$ Congresso Brasileiro de Ciências da Comunicação [Internet]; 2017 set. 4-9; Curitiba, PR. São Paulo: Intercom; 2007 [acesso 2021 mar 5]. Disponível em: https://portalintercom.org. br/anais/nacional2017/resumos/R12-2158-1.pdf

7. Foucault M. A ordem do discurso [Internet]. Rio de Janeiro: Ciberfil; 2002 [acesso 2021 fev 20]. Disponível em: http://www2.eca.usp.br/Ciencias.Linguagem/ Foucault_OrdemDoDiscurso.pdf

8. Massarani L, Leal T, Waltz I. O debate sobre vacinas em redes sociais: uma análise exploratória dos links com maior engajamento. Cad Saúde Pública. 2020;36(Supl. 2):e00148319. doi: https://doi.org/10.1590/0102$311 \times 00148319$

9. Sofiatti F, Maissiat J. Tecnologias digitais e educação infantil: formação continuada de professores para o uso dos instrumentos digitais no ato pedagógico [Internet]. Vitória (ES): Instituto Federal de Educação, Ciência e Tecnologia do Espírito Santo, 2019 [acesso 2021 mar 23]. Disponível em: https://educapes.capes.gov.br/bitstream/ capes $/ 559891 / 2 /$ Fernanda\%20Sofiatti_Produto\%20 Educacional_Humanidades.pdf

10. Monari ACP, Bertoli Filho C. Saúde sem fake news: estudo e caracterização das informaçôes falsas divulgadas no canal de informação e checagem de fake news do Ministério da Saúde. Rev Mídia Cotidiano. 2019;13(1):160-86. doi: https://doi.org/10.22409/ ppgmc.v13i1.27618

11. Thuler LCS, Hartz Z. Big data em pesquisas populacionais sobre câncer: desafios e oportunidades. Rev Bras Cancerol. 2019;65(4):e-03718. doi: https:// doi.org/10.32635/2176-9745.RBC.2019v65n4.718

12. Marconi F. Newsmakers: artificial intelligence and the future of journalism. New York: Columbia University Press; 2020.

13. Araújo LV. Adoção de algoritmos, NGL e inteligência artificial na imprensa brasileira em âmbito nacional e regional. Estud J Mídia. 2017;14(2):175-88. doi: https:// doi.org/10.5007/1984-6924.2017v14n2p175

14. Lee KF. Inteligência artificial: como os robôs estão mudando o mundo, a forma como amamos, nos relacionamos, trabalhamos e vivemos. Rio de Janeiro: Globo Livros; 2019.

15. Usher N. Interactiv journalism: hackers, data, and code. Illinois: University of Illinois Press; 2016.

16. Mulligan M. Want to produce hirable grads, journalism schools? Teach them to code. NiemanLab [Internet]. 2012 Sept 5 [cited 2020 Dec 20];Back to school: the evolution of journalism education. Available from: https://www.niemanlab.org/2012/09/miranda-mulliganwant-to-produce-hirable-grads-journalism-schoolsteach-them-to-code/

17. Diakopoulos N. Automating the news: how algorithms are rewriting the media. Cambridge, MA: Harvard University Press; 2019.

18. Amaral Filho N. Tecnologias e a crise da democracia: desafios à prática e ao ensino do Jornalismo no Brasil. Corresp Anál. 2019;(10). doi: https://doi.org/10.24265/ cian.2019.n10.02 